\title{
A case report of nonepisodic angioedema with eosinophilia in a Korean patient and a review of the Korean literature
}

\author{
Ji Sun Jang, M.D., Chang-Hwan Kim, M.D., Sang-Seok Kim, M.D. ${ }^{2}$, \\ Ji Eun Oh, M.D., Yong-Bum Park, M.D., Jae-Young Lee, M.D. and Eun-Kyung Mo, M.D. \\ Departments of Internal Medicine and Dermatology², College of Medicine, Hallym University, Seoul, Korea
}

\begin{abstract}
Episodic angioedema with eosinophilia (EAE) is characterized by recurrent angioedema, peripheral eosinophilia, elevated serum IgM, fever, weight gain, and a benign course lacking any internal organ involvement. Dozens of cases of the nonepisodic variant (NEAE), which is limited to a single attack, have been reported in Japan. These NEAE cases normally have been less severe than the episodic type. In this paper, we describe the case of a Korean patient whose clinical and laboratory findings were consistent with NEAE, and review five other cases of EAE and NEAE reported in the Korean literature. The Korean NEAE cases outlined in this paper demonstrate that, as in Japan, NEAE is not uncommon in Korea, and also suggest that this disease exhibits a cultural predilection for Asian populations.
\end{abstract}

Key Words : Angioedema, Eosinophilia

\section{INTRODUCTION}

Episodic angioedema with eosinophilia (EAE), originally described by Gleich et al. in 1984", is a syndrome characterized by recurrent episodes of angioedema, fever, leukocytosis, eosinophilia, elevated serum IgM, increased body weight, and a benign clinical course lacking any internal organ involvement. Many other cases have been detected since this initial report, and this syndrome has been recognized as a distinct clinical entity ${ }^{2,3)}$. More than 40 cases with symptomatic presentations and laboratory findings similar to EAE have been reported, but these cases have not involved recurrent attacks, and thus have been subsequently designated as nonepisodic angioedema with eosinophilia $(\mathrm{NEAE})^{4-8)}$. The majority of these NEAE cases have been reported in Japanese patients, with the exception of three cases reported in the Korean literature ${ }^{7-9)}$. No cases have yet been reported in Western populations. This ethnic or regional distribution may be an important characteristic of NEAE. In this paper, we describe a patient whose clinical and laboratory features were similar to those observed in previous cases of NEAE, and also present our review of cases thus far reported in Korea.

\section{CASE REPORT}

A 26-year-old Korean woman presented with edema of her hands and lower legs, which had developed 2 weeks prior to her hospital visit. Her body weight had increased by $2 \mathrm{~kg}$ over those 2 weeks, and this was her first episode of the reported symptoms. The edema was distributed symmetrically on both of the patient's upper and lower extremities, and was pitted. She denied any febrile sensation and had a pruritic rash on her lower legs (Figure $1 \mathrm{~A}-1 \mathrm{C}$ ), and had also experienced mild joint pain in both knees 1 week after the onset of the edema. Her family and past medical histories, including any allergic diseases, were unremarkable. She also denied taking any drugs, including Oriental medications, with the exception of one acetaminophen tablet $(300 \mathrm{mg}) 1$ week prior to the onset of edema. Her

- Received : April 28, 2006

- Accepted : May 29, 2006

- Correspondence to : Jae-Young Lee, M.D., Ph.D., Department of Internal Medicine, College of Medicine, Hallym University, Department of Internal Medicine, Kangdong Sacred Heart Hospital 445 Gil-Dong, Gangdong-Gu, Seoul 134-701, Korea Tel : 82-2-2225-2750, Fax : 82-2-478-6925, E-mail : jaeyoung@ @allym.ac.kr 

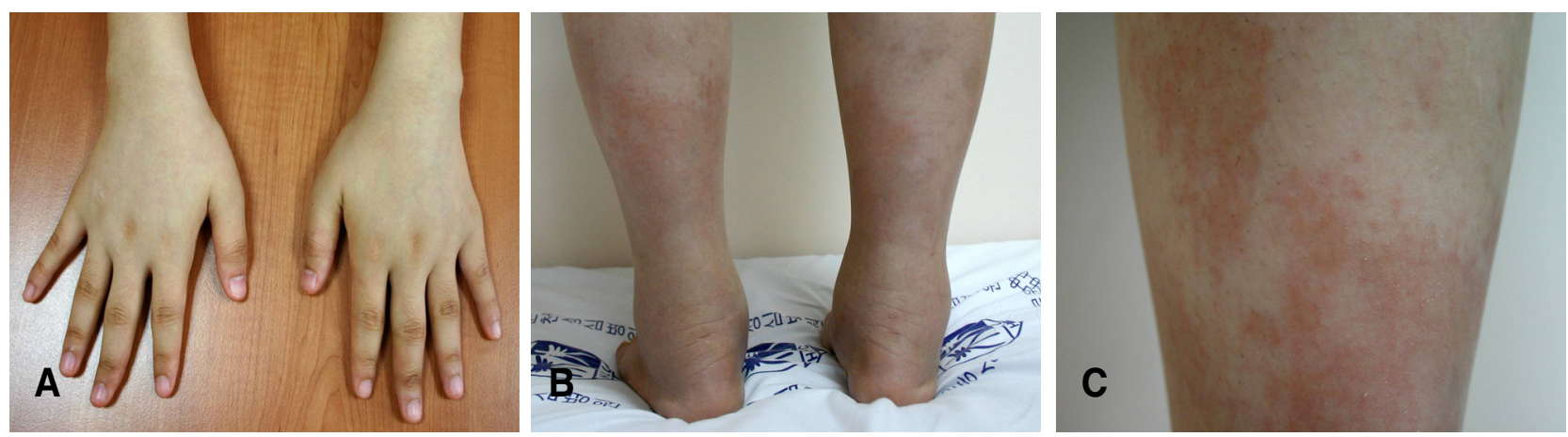

Figure 1. (A) Edema of both hands. (B) Edema of both lower legs and feet. Pruritic eruptions were also noted. (C) Pruritic eruptions on the lower legs.
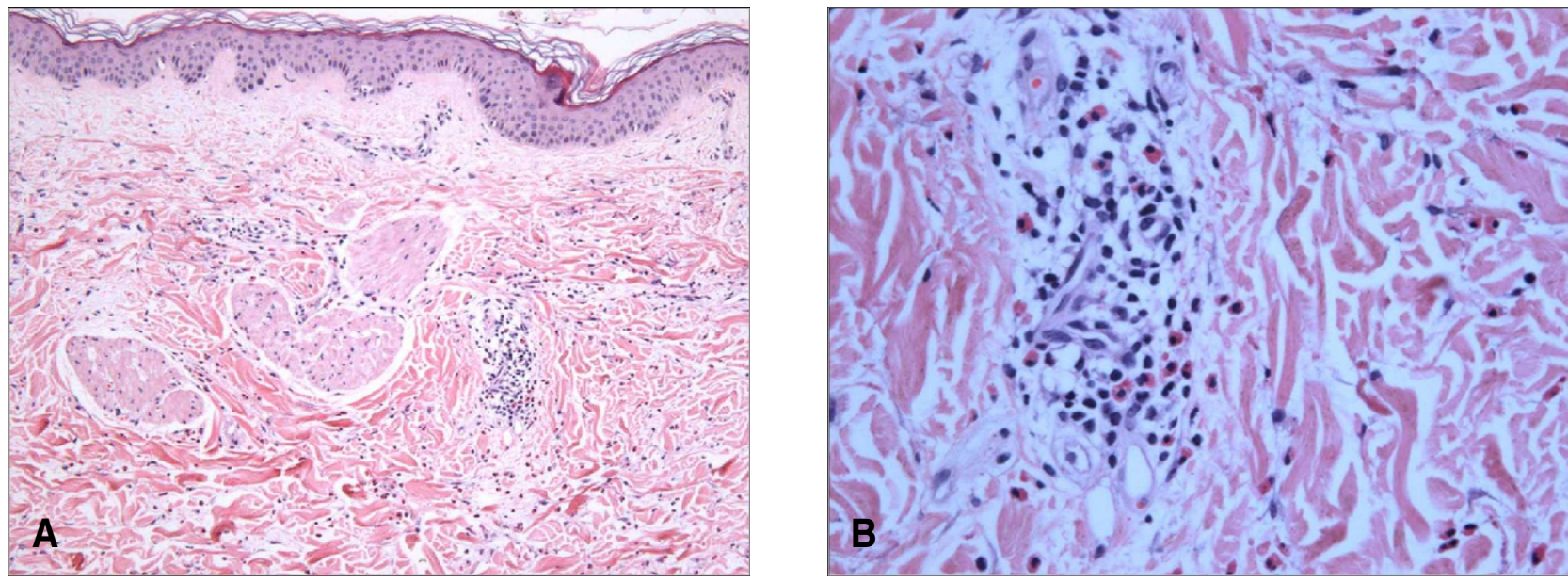

Figure 2. (A) Skin biopsy section, taken from a skin lesion on the left lower extremity, shows perivascular eosinophil infiltration. (H\&E, $x 100)$. (B) (H\&E, x400).

symptoms did not appear to be related to her menstrual cycle.

Laboratory tests revealed leukocytosis $\left(12,250 / \mathrm{mm}^{3}\right.$; normal range: $4,000-10,000 / \mathrm{mm}^{3}$ ) with $51.5 \%$ eosinophils (normal range: $0 \sim 7 \%$ ) in the peripheral blood. The eosinophil count was $6,300 / \mathrm{mm}^{3}$. Serum $\mathrm{IgE}$ had increased to $1,423 \mathrm{IU} / \mathrm{mL}$ (normal range: $0-170 \mathrm{IU} / \mathrm{mL}$ ), but $\lg A$, IgG, and $\operatorname{lgM}$ levels were all within normal limits. Antinuclear antibody was negative, as were stool ova and serum antibodies to parasites. No clinical findings were suggestive of autoimmune disease or parasite infestation. No abnormal findings were observed in the serum chemistry that would be reflective of renal or hepatic dysfunction. No proteinuria was detected. The rash on the patient's lower legs was examined histologically, and identified as perivascular eosinophil infiltration (Figure 2). Lymphocyte phenotyping was conducted, but did not indicate the presence of any abnormal lymphocyte clones.

We diagnosed the patient with NEAE, and prescribed an oral antihistamine to control the pruritus. One week after the patient began taking antihistamines, the edema and rash began to evidence improvements. The knee arthralgia also clearly improved. The eosinophil count decreased to $1,530 / \mathrm{mm}^{3}$ after 2 weeks and to $736 / \mathrm{mm}^{3}$ after 8 weeks. The patient was free of symptoms at 4 months, and had an eosinophil count of $550 / \mathrm{mm}^{3}$. We followed the patient for 18 months, and observed no recurrence of either the symptoms or the eosinophilia (the eosinophil count was $180 / \mathrm{mm}^{3}$ ).

\section{DISCUSSION}

Our patient presented with eosinophilia with angioedema localized to the upper and lower extremities, and evidenced features typical of the NEAE cases thus far reported in Japan. That is, the patient was a young female exhibiting a mild weight gain, and her condition lacked internal organ involvement, improved without corticosteroids, involved no increase in $\operatorname{lgM}$ levels, and did not recur over the course of 18 months. The skin biopsy indicated perivascular eosinophil infiltration. 
Table 1. Review of reported cases of nonepisodic angioedema with eosinophilia in Korea

\begin{tabular}{|c|c|c|c|c|c|c|c|c|c|c|c|}
\hline \multirow{2}{*}{\multicolumn{2}{|c|}{$\begin{array}{c}\text { Case } \\
\text { Reference }\end{array}$}} & \multirow[b]{2}{*}{$\begin{array}{l}\text { Onset- } \\
\text { age/sex }\end{array}$} & \multirow[b]{2}{*}{ fever } & \multicolumn{2}{|c|}{ Clinical symptoms } & \multirow[b]{2}{*}{ arthralgia } & \multicolumn{3}{|c|}{ Laboratory tests } & \multirow[b]{2}{*}{$\begin{array}{c}\text { IgM } \\
(\mathrm{mg} / \mathrm{dL})\end{array}$} & \multirow[b]{2}{*}{$\begin{array}{c}\text { Recurrence } \\
\text { (or Steroid } \\
\text { dependency) }\end{array}$} \\
\hline & & & & $\begin{array}{l}\text { weight } \\
\text { gain }\end{array}$ & $\begin{array}{l}\text { skin } \\
\text { lesion }\end{array}$ & & $\begin{array}{l}\text { White } \\
\text { blood cells } \\
\left(/ \mathrm{mm}^{3}\right)\end{array}$ & $\begin{array}{l}\text { Eosinophils in } \\
\text { the peripheral } \\
\text { blood }\left(/ \mathrm{mm}^{3}\right)\end{array}$ & $\begin{array}{c}\lg E \\
(I U / m L)\end{array}$ & & \\
\hline 1 & $\begin{array}{l}\text { Ko } \\
\text { et al.(7) }\end{array}$ & $28 / F$ & - & $5 \mathrm{~kg}$ & + & - & 14,690 & $7,536(51.3 \%)$ & - & - & - \\
\hline 2 & $\begin{array}{l}\text { Park } \\
\text { et al.(8) }\end{array}$ & $36 / F$ & - & - & - & - & 14,400 & $6,910(48 \%)$ & $(1,769)$ & - & - \\
\hline 3 & $\begin{array}{l}\text { Park } \\
\text { et al.(8) }\end{array}$ & $16 / \mathrm{M}$ & - & $7 \%(4.6 \mathrm{~kg})$ & - & - & 30,300 & $16,665(55 \%)$ & - & (403) & + \\
\hline 4 & $\begin{array}{l}\text { Jung } \\
\text { et al.(9) }\end{array}$ & $29 / F$ & - & - & - & - & 28,200 & $17,200(61 \%)$ & ND & (239) & $\begin{array}{l}\text { Steroid } \\
\text { dependent }\end{array}$ \\
\hline 5 & $\begin{array}{l}\text { Yang } \\
\text { et al.(17) }\end{array}$ & $34 / F$ & + & $8 \%$ & - & - & 16,580 & $8,730(62 \%)$ & - & (344) & + \\
\hline 6 & $\begin{array}{l}\text { present } \\
\text { case }\end{array}$ & $26 / F$ & - & $2 \mathrm{~kg}$ & + & + & 12,250 & $6,300(51 \%)$ & $(1,423)$ & - & - \\
\hline
\end{tabular}

$N D$ Not done, $F$ female, $M$ male

EAE is characterized by recurrent edema and requires the administration of corticosteroids, and has also been reported principally in Europe and the United States. However, in Japan and Korea, more than 40 cases have been reported with clinical symptoms similar to those observed in EAE, but without recurrent episodes; these patients recovered without corticosteroid treatment ${ }^{4-8}$. Chikama et al. first gave this distinct form of EAE the designation $N E A E^{4)}$, which has been loosely identified as a less severe form of $E A E^{6)}$. The most notable aspect of NEAE is the absence of recurrence, but several other differences also exist with regard to the clinical features of NEAE and EAE. One of these differences is the distribution of the edema. In NEAE, the angioedema is normally localized to the hands and the proximal portion of the lower legs, as in the present case, whereas in $E A E$, the angioedema frequently extends farther down the extremities, sometimes including the face ${ }^{10)}$. The edema in EAE is attended by a substantial increase in body weight. An increase in serum IgM levels is also normally detected in cases of $E A E$, but is seldom observed in $N E A E^{6,10}$. Almost all $E A E$ patients require corticosteroid therapy, whereas spontaneous remission frequently occurs in patients suffering from NEAE. Additionally, all NEAE patients thus far have been young females, as in the case described herein ${ }^{4-8)}$.

The pathogenesis of EAE and NEAE remains to be thoroughly elucidated. The cause of the sudden increase of eosinophils remains unknown, as with idiopathic hypereosinophilic syndrome. The identification of abnormal clonal $\mathrm{CD}^{-} \mathrm{CD}^{+}$cells in the blood of some EAE sufferers ${ }^{11)}$ indicates that EAE and NEAE may be, in some if not all patients, a disease that involves abnormal $\mathrm{T}$ cell clones, similarly to the lymphocytic variant of hypereosinophilic syndrome ${ }^{12)}$. The predilection to affect the skin with an absence of internal organ involvement in EAE and NEAE is also a clinical feature reminiscent of the lymphocytic variant of hypereosinophilic syndrome ${ }^{12)}$. In the case described herein, we conducted lymphocyte phenotyping in order to determine the presence of any aberrant clonal lymphocytes, as has been observed in cases of the lymphocytic variant of hypereosinophilic syndrome ${ }^{13)}$. However, our results in this regard were negative. The angioedema of EAE and NEAE is likely associated with a temporal increase in the vascular permeability of local capillaries via some mediators, including antiendothelial cell antibodies and cytokines ${ }^{3,14-16)}$. Several reports have shown that histamine levels are within normal limits, and that $\mathrm{IL}-1, \mathrm{IL}-5$, and $\mathrm{IL}-6$ generated by monocytes, endothelial cells, $T$ cells, and eosinophils increase during the acute phase of $\mathrm{EAE}^{3,5,11,15,16)}$. According to a recent report, $\mathrm{IL}-5$ levels were determined to be lower, and TNF-alevels were higher in the acute phase of NEAE than in the acute phase of EAE. Thus, the cytokine profile may be related with the existence or absence of recurrent attacks ${ }^{5)}$.

Recently, several cases of EAE and NEAE have been reported in $\mathrm{Korea}^{7-9,17)}$. Table 1 shows these six cases of EAE and NEAE, including the case described in this paper. Cases 1, 2 , and the present case were readily diagnosed as NEAE, 
whereas cases 3 and 5 were thought to be EAE. In case 4, certain aspects, such as the elevated serum IgM level and the necessity for corticosteroid therapy to control the symptoms, supported a diagnosis of EAE. However, the presence of other aspects, including the fact that it occurred in a young female, the absence of weight gain, and the absence of a previous episode or recurrence, was suggestive of NEAE. This series of NEAE and EAE case reports from Korea demonstrates that NEAE and EAE are not rare diseases within the Korean population, and also suggests that NEAE may have a racial predisposition toward Asian populations.

In this work, we have described the case of a Korean patient with NEAE and have reviewed five other cases of NEAE and EAE occurring in Korean patients. As in the Japanese population, NEAE is not an uncommon disease within the Korean population. Further studies will be required in order to clarify the pathogenesis of NEAE.

\section{REFERENCES}

1) Gleich GJ, Schroeter AL, Marcoux JP, Sachs MI, O'Connell EJ, Kohler PF. Episodic angioedema associated with eosinophilia. N Engl J Med 310:1621-1626, 1984

2) Wolf $\mathrm{K}$, Pehamberger $\mathrm{H}$, Breyer $\mathrm{S}$, Leiferman $\mathrm{KM}$, Wolff $\mathrm{K}$. Episodic angioedema with eosinophilia. J Am Acad Dermatol 20:21-27, 1989

3) Tillie-Leblond I, Gosset $P$, Janin $A$, Salez F, Prin L, Tonnel AB. Increased interleukin-6 production during the acute phase of the syndrome of episodic angioedema and hypereosinophilia. Clin Exp Allergy 28:491-496, 1998

4) Chikama R, Hosokawa M, Miyazawa T, Miura R, Suzuki T, Tagami $\mathrm{H}$. Nonepisodic angioedema associated with eosinophilia: report of 4 cases and review of 33 young female patients reported in Japan. Dermatology 197:321-325, 1998

5) Mizukawa $Y$, Shiohara T. The cytokine profile in a transient variant of angioedema with eosinophilia. British J Dermatol 144:169-174, 2001
6) Matsuda M, Fushimi T, Nakamura A, Ikeda S. Nonepisodic angioedema with eosinophilia: a report of two cases and a review of the literature. Clin Rheumatol 25:422-425, 2006

7) Ko WK, Yun YY, Park JW, Park JM, Kang HY, Cho SH, Hong CS. A case of angioedema associated with eosinophilia. J Asthma Allergy Clin Immunol 19:504-508, 1999

8) Park CS, Lee SS, Lim JW, An JM, Lee TH, Cho YS, Moon HB. Two different cases of episodic angioedema with eosinophilia. Korean $\mathrm{J}$ Med 69:706-710, 2005

9) Jung YH, Oh HS, Yoon YJ, Kim KH, Lee YM, Kim YK, Un ST, Park CS. A case of nonepisodic angioedema associated with eosinophila. J Asthma Allergy Clin Immunol 25:73-76, 2005

10) Shikiji T, Urano $Y$, Takiwaki H, Arase S. A case of episodic angioedema associated with eosinophilia. J Med Invest 44:103-108, 1997

11) Zenone $T$, Felman $P$, Malcus $C$, Durieu I, Durand DV. Indolent course of a patient with hypereosinophilic syndrome associated with clonal T-cell proliferation. Am J Med 107:509-511, 1999

12) Roufosse F, Cogan E, Goldman M. Recent advances in pathogenesis and management of hypereosinophilic syndromes. Allergy 59:673-689, 2004

13) Simon HU, Plotz SG, Dummer R, Blaser K. Abnormal clones of $T$ cells producing interleukin-5 in idiopathic eosinophilia. N Engl J Med 341:1112-1120, 1999

14) Lassalle $P$, Gosset $P$, Gruart $V$, Prin L, Capron M, Lagrue G, Kusnierz JP, Tonnel AB, Capron A. Presence of antibodies against endothelial cells in the sera of patients with episodic angioedema and hypereosinophilia. Clin Exp Immunol 82:38-43, 1990

15) Putterman C, Barak V, Caraco Y, Neuman T, Shalit M. Episodic angioedema with eosinophilia: a case associated with $T$ cell activation and cytokine production. Ann Allergy 70:243-248, 1993

16) Morgan SJ, Prince HM, Westerman DA, McCormack C, Glaspole I. Clonal T-helper lymphocytes and elevated IL-5 levels in episodic angioedema and eosinophilia (Gleich's syndrome). Leuk Lymphoma 44:1623-1625, 2003

17) Yang HM, Chung JW, Song HJ, Choi JH, Suh $Y J$, Suh $\mathrm{CH}$, Nahm $\mathrm{DH}$, Park HS. A case of episodic angioedema with eosinophilia. J Asthma Allergy Clin Immunol 22:751-754, 2002 